\title{
Frequent pain in older people with and without diabetes - Finnish community based study
}

\author{
M. Karjalainen ${ }^{1,2}$, J. Saltevo $^{3}$, M. Tiihonen ${ }^{4^{*}}$ (D) M. Haanpää5,6, H. Kautiainen ${ }^{7,8}$ and P. Mäntyselkä ${ }^{1,8}$
}

\begin{abstract}
Background: The association between pain and diabetes in older people has been largely unexplored. The aim of this survey was to analyze the prevalence and characteristics of pain among Finnish men and women 65 or older with and without diabetes in primary care.

Methods: All home-dwelling persons 65 years or older with diabetes $(N=527)$ and age and gender matched controls $(N=890)$ were identified from electronic patient records. Frequent pain was regarded as any pain experienced more often than once a week, and it was divided into pain experienced several times a week but not daily and pain experienced daily or continuously. The Numeric Rating Scale (0-10) (NRS) was used to assess the intensity and interference of the pain.

Results: The number of subjects who returned the questionnaire was 1084 (76.5\%). The prevalence of frequent pain in the preceding week was 50\% among women without diabetes and 63\% among women with diabetes (adjusted, $p=0.22$ ). In men, the corresponding proportions were $42 \%$ without diabetes and $47 \%$ with diabetes (adjusted, $p=0.58$ ). In both genders, depressive symptoms and the number of comorbidities were associated with pain experienced more often than once a week and with daily pain. Diabetes was not associated with pain intensity or pain interference in either women or men.
\end{abstract}

Conclusions: Pain in older adults is associated with depressive symptoms and the number of comorbidities more than with diabetes itself.

Keywords: Diabetes, Older people, Pain

\section{Background}

Diabetes is among the most common chronic diseases in the world and in Finland [1]. The global prevalence of diabetes has nearly doubled from 1980 to 2014, increasing from $5 \%$ to $9 \%$ in the adult population [2]. In Finland the prevalence of diabetes is estimated to be $11 \%$. Most patients with diabetes in Finland have type 2 diabetes (89\%) [3]. The increasing incidence and prevalence of diabetes will inevitably result in accumulation of diabetes in older people [4]. It is assumed that people with diabetes have a bigger load of diseases than people without diabetes [5].

\footnotetext{
* Correspondence: miia.tiihonen@uef.fi

${ }^{4}$ School of Pharmacy, University of Eastern Finland, P.O. BOX 1627, FI-70211

Kuopio, Finland

Full list of author information is available at the end of the article
}

One important comorbid condition often linked to diabetes is chronic pain. In general, it is very common in the adult population [6, 7]. Chronic pain may be related to general multimorbidity [8] and even to mortality [9]. Patients with type 2 diabetes have an increased risk of developing specific rheumatic manifestations caused by diabetes, such as stiff hand syndrome, Dupuytren's disease, tenosynovitis, carpal tunnel syndrome, shoulder capsulitis/periarthritis, and reduced joint mobility. In addition to the conditions probably caused by diabetes, obesity and physical inactivity may predispose to osteoarthritis [10], which therefore most likely is associated with rather than caused by the disease.

A clinically important complication of diabetes is neuropathy, which can be painful. The prevalence of neuropathic pain in people with diabetes is difficult to 
estimate, as definitions have varied enormously between studies. In an observational study of a large cohort of patients with diabetes in the U.K. the prevalence of painful neuropathy symptoms was estimated to be as high as $34 \%$ [11]. Furthermore, non-neuropathic pain is common among patients with diabetes [12].

Data on the pain of older people with diabetes are few. Cross-sectional data from a multi-site, prospective cohort study of 11,689 participants with diabetes aged 47-73 years in the United States found that moderate to extreme pain was present in $58 \%$ and pain was strongly associated with poorer mental health and physical functioning but not poorer glycemic control [13]. Another population study based on in-person interviews of adults 65 years old or older in the USA found that bothersome pain in the last month was reported by half of the adult population, while the corresponding prevalence among people with diabetes was $61.5 \%$ [14]. In Taiwan, a large population-based, retrospective cohort study found that people aged 18-50 years with type 2 diabetes had a higher 10-year cumulative incidence of and a higher mean number of doctor visits for musculoskeletal pain than a non-diabetic group [15]. Regardless of the etiology, musculoskeletal complaints are frequent among patients with diabetes mellitus type 2 and may be of major importance in terms of quality of life [16].

Both diabetes and chronic pain are more common among older people than younger people. It can be assumed that older people with diabetes may suffer pain and be affected by pain more than those without diabetes. However, the association between diabetes and pain in old people with a control group of people without diabetes has not been studied much. Therefore, the aim of this study was to analyze the prevalence, frequency, intensity and interfering effect of pain among women and men aged 65 or more with and without diabetes in a community-based population setting.

\section{Methods}

\section{Study population}

This cross-sectional study is based on ISDM (Inner-Savo Diabetes Mellitus) data. The data is obtained from the Inner-Savo district with a total population of 10,793. The present study was designed to collect data from a semirural community in order to have information for planning the services for older inhabitants. The study was approved by the Inner Savo Health Care Federation of Municipalities (61 A/2015). The study protocol of the ISDM study was approved by the Research Ethics Committee of the Northern Savo Hospital District, Kuopio, Finland (256/2015). The questionnaire included information letter about the use of data and returning of questionnaire was voluntary. The autonomy of research subjects was respected and only anonymous data were analyzed. No harm was possible for the subjects and confidentiality of the subjects and research data were protected. Of the inhabitants, 3093 (29\%) were 65 or older representing a semi-rural area of Finland with a larger proportion of older people than in larger cities and average in Finland (20\%) [17].

Home-dwelling, 65 years or older persons with diabetes (and with Haemoglobin A1c (HbA1c) -levels) were identified from primary care electronic patient records using the International Classification of Diseases (ICD-10) diagnostic codes E10 and E11 [18]. Because only 12 subjects had type 1 diabetes people with type 1 and type 2 diabetes were combined. For each person with a diagnosis of diabetes, two control persons matched by age and gender were identified (Fig. 1). A total of 1417 questionnaires were handed out to 527 persons with diabetes and 890 persons without diabetes from August to September 2015. The study participants filled out a structured questionnaire including background variables, e.g., gender, age, and living arrangements (living alone or with someone, in a rural or urban area, in their own house, an apartment, or in supported living).

\section{Measurements and tools}

Pain was defined as any pain experienced in the preceding week $[7,19]$. Localizations of pain were recorded according to a list (head, thorax, abdomen, neck, shoulder, arm, other region of the upper limb, low back, hip, knee, other region of the lower limb, somewhere else). Pain experienced more often than once a week was regarded as frequent pain. Further, frequent pain was divided into pain experienced several times a week but not daily and pain experienced daily or continuously. Thus, three categories of pain were used in the analyses; (1) no frequent pain; (2) pain several times a week; and (3) daily or continuous pain. The Numeric Rating Scale (NRS) was used to assess the intensity and general interference of the pain with the general activity [20]. Respondents were asked to rate their pain intensity and interference on a scale 0 to 10 , with 0 being no pain or no interference at all and 10 being the worst imaginable pain or a complete interference. The duration of pain was asked and chronic pain was defined as pain with the duration of at least 3 months.

The questionnaire included lifestyle items regarding physical activity based on the Kasari-FIT index with three questions on the frequency, efficiency, and duration of exercise [21]. We measured lifestyle items regarding alcohol consumption and smoking with the Alcohol Use Disorders Identification Test (AUDIT-C) [22]. An alcohol user was defined as a person using alcohol at least once a month. To assess depressive symptoms, the 15-item Geriatric Depression Scale (GDS-15) was used [23]. 


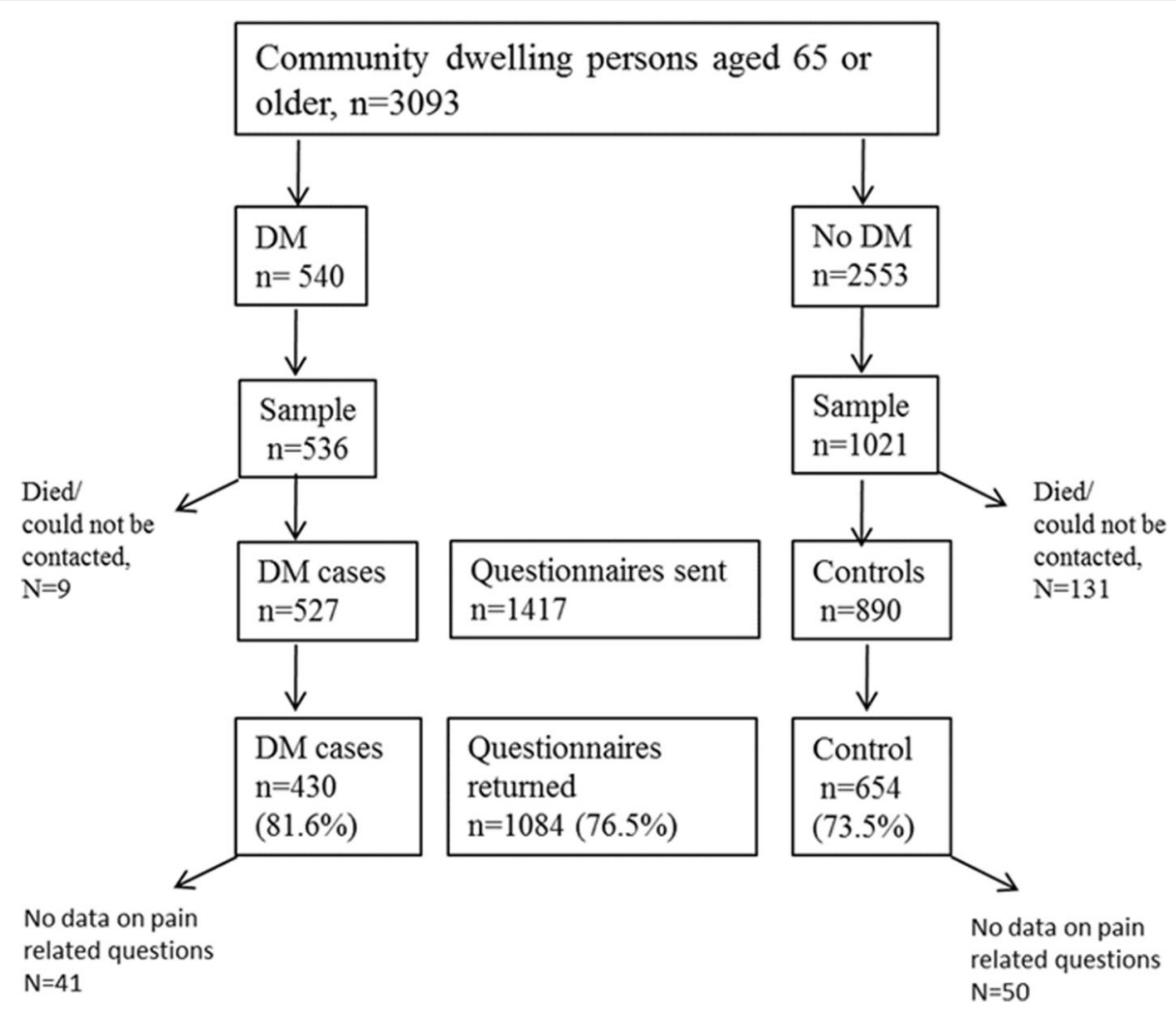

Fig. 1 Flow chart of the study

The subjects were asked to report long-term diseases they had according to a list including the most common chronic diseases: High blood pressure, cardiovascular disease, cancer, rheumatoid arthritis, osteoarthritis, chronic spine disease, asthma/COPD, mental illness, hypothyroidism. The reported diseases were summed up to represent the number of chronic diseases (number of comorbidities). In the subjects with diabetes, the number of comorbidities means those in addition to diabetes. The mean HbA1c level was based on the recordings of the electronic patient record data in the preceding year.

\section{Statistical analysis}

Because men and women are potentially different in terms of pain and diabetes, all the analyses were conducted separately for men and women. The baseline sample characteristics are presented as amounts and percentages for categorical variables and means with standard deviations for continuous variables. Statistical comparisons between the groups were made using the t-test, chi-square test, or analysis of variance. Multinominal (polytomous) logistic regression analyses were performed to identify demographic, clinical, and functional factors associated with weekly and daily pain. A bootstrap method was used when the theoretical distribution of the test statistics was unknown or in the case of a violation of the assumptions (e.g. non-normality). Adjusted curvilinear relationships between $\mathrm{HbA1c}$ and intensity and interference of pain were derived from regression models including quadratic term of $\mathrm{HbA} 1 \mathrm{C}$. Bootstrap estimation was used to derive a 95\% confidence interval of adjusted curvilinear correlation. The normality of the variables was tested by using the Shapiro-Wilk W test. No adjustment for multiple comparisons was considered necessary. The Stata 14.1, StataCorp LP (College Station, TX, USA) statistical package was used for the analysis.

\section{Results}

A total of 1084 (76.5\%) questionnaires were returned (Fig. 1). Among the subjects with diabetes, the response rate was $81.6 \%(N=430)$ and among the controls, respectively, $73.5 \%(N=654)(p<0.001)$. Complete data were available for 993 participants (70.0\% of the sample).

The characteristics of the study subjects are shown in Table 1 . Females with diabetes were 2 years older than the controls. A slightly but significantly smaller proportion of men with diabetes lived in a detached house compared with men without diabetes. Ability to move without aid and physical activity were lower and hypertension and cardiovascular disease and number of 
Table 1 Characteristics of the participating women and men with and without diabetes

\begin{tabular}{|c|c|c|c|c|c|c|}
\hline & \multicolumn{3}{|l|}{ Women } & \multicolumn{3}{|l|}{ Men } \\
\hline & $\begin{array}{l}\text { No diabetes } \\
N=329\end{array}$ & $\begin{array}{l}\text { Diabetes } \\
N=198\end{array}$ & $P$-value & $\begin{array}{l}\text { No diabetes } \\
N=275\end{array}$ & $\begin{array}{l}\text { Diabetes } \\
N=191\end{array}$ & $P$-value \\
\hline Age, mean (SD) & $75(7)$ & $77(8)$ & 0.002 & $73(5)$ & $74(6)$ & 0.26 \\
\hline Living in a detached house, n (\%) & $256(78)$ & $144(73)$ & 0.19 & $239(87)$ & $152(80)$ & 0.034 \\
\hline Living in the countryside, $\mathrm{n}(\%)$ & $90(28)$ & $54(29)$ & 0.85 & $109(40)$ & $70(38)$ & 0.60 \\
\hline Living alone, n (\%) & $132(40)$ & $95(48)$ & 0.078 & $60(22)$ & $44(23)$ & 0.76 \\
\hline Physical activity, Kasari-FIT Index, mean (SD) & $38(22)$ & $26(19)$ & $<0.001$ & $43(23)$ & $33(23)$ & $<0.001$ \\
\hline Smoking, n (\%) & $16(5)$ & $6(3)$ & 0.31 & $45(16)$ & $15(8)$ & 0.007 \\
\hline Alcohol use, AUDIT-C, mean (SD) & $1.34(1.45)$ & $0.92(1.33)$ & $<0.001$ & $2.92(2.58)$ & $2.75(2.35)$ & 0.49 \\
\hline Depressive symptoms, GDS-15, mean (SD) & $2.5(2.8)$ & $3.8(3.0)$ & $<0.001$ & $2.6(3.0)$ & $3.1(3.0)$ & 0.13 \\
\hline \multicolumn{7}{|l|}{ Comorbidities, n (\%) } \\
\hline High blood pressure & $180(55)$ & $149(75)$ & $<0.001$ & $128(47)$ & $129(68)$ & $<0.001$ \\
\hline Cardiovascular disease & $44(13)$ & $47(24)$ & 0.002 & $45(16)$ & $40(21)$ & 0.21 \\
\hline Cancer & $20(6)$ & $10(5)$ & 0.62 & $20(7)$ & $13(7)$ & 0.85 \\
\hline Rheumatoid arthritis & $19(6)$ & $9(5)$ & 0.54 & $10(4)$ & $6(3)$ & 0.77 \\
\hline Osteoarthritis & $97(29)$ & $73(37)$ & 0.079 & $62(23)$ & $50(26)$ & 0.37 \\
\hline Chronic spine disease & $95(29)$ & $55(28)$ & 0.79 & $52(19)$ & $44(23)$ & 0.28 \\
\hline Asthma/COPD & $45(14)$ & $34(17)$ & 0.28 & $20(7)$ & $22(12)$ & 0.12 \\
\hline Mental illness & $40(12)$ & $32(16)$ & 0.20 & $22(8)$ & $19(10)$ & 0.46 \\
\hline Hypothyroidism & $71(22)$ & $53(27)$ & 0.17 & $17(6)$ & $15(8)$ & 0.48 \\
\hline Number of comorbidities, mean (SD) & $1.9(1.4)$ & $2.3(1.5)$ & $<0.001$ & $1.4(1.3)$ & $1.8(1.4)$ & 0.002 \\
\hline Any pain, n (\%) & $236(72)$ & $163(82)$ & 0.006 & $193(70)$ & $129(68)$ & 0.054 \\
\hline \multicolumn{7}{|l|}{ Pain localization, n (\%) } \\
\hline Low back & $120(36)$ & $83(42)$ & 0.21 & $68(25)$ & $52(27)$ & 0.54 \\
\hline Shoulder & $71(22)$ & $74(34)$ & $<0.001$ & $66(24)$ & $49(26)$ & 0.68 \\
\hline Knee & $98(30)$ & $77(39)$ & 0.032 & $60(22)$ & $43(23)$ & 0.86 \\
\hline Hip & $81(25)$ & $64(32)$ & 0.055 & $47(17)$ & $37(19)$ & 0.53 \\
\hline Other lower extremity & $77(23)$ & $61(31)$ & 0.061 & $44(16)$ & $36(19)$ & 0.42 \\
\hline Neck & $101(31)$ & $54(27)$ & 0.40 & $59(21)$ & $42(22)$ & 0.89 \\
\hline Other upper extremity & $22(7)$ & $24(12)$ & 0.032 & $15(5)$ & $10(5)$ & 0.92 \\
\hline
\end{tabular}

SD Standard deviation, Kasari-FIT index person's level of physical activity (Frequency, Intensity, Time), Alcohol user alcohol use at least once a month according to the Alcohol Use Disorders Identification Test (AUDIT-C), GDS-15 Geriatric Depression Scale, COPD chronic obstructive pulmonary disease

comorbidities were higher among persons with diabetes in both genders. Smoking was less common among men with diabetes than among controls, while women used less alcohol than those without diabetes. Compared with people without diabetes, women with diabetes had more depressive symptoms.

In general, women with diabetes experienced pain more often than women without diabetes. A corresponding difference was not found in men. Women with diabetes more often had pain in their shoulders, knees, and upper extremities than women without diabetes. There were no corresponding significant differences in pain localizations in men.

Frequent pain was experienced less often by women without diabetes than by those with diabetes (Fig. 2).
However, after adjustment for age, physical activity, depressive symptoms, alcohol use, smoking, and number of comorbidities, no difference was found. In men, there was not any significant difference in the presence of frequent pain. Among the women with frequent pain, chronic pain was found in $94 \%(155 / 165)$ of those without diabetes and in 94\% (116/124) with diabetes $(p=0.89)$. Respectively, in men, pain was chronic in $91 \%$ without diabetes and $94 \%$ with diabetes $(p=0.40)$.

The distribution of pain according to frequency is presented in Fig. 3. The crude prevalence of daily pain in women was $19.8 \%(N=65)$ without diabetes and $33.3 \%$ $(N=66)$ with diabetes $(p=0.002)$. The corresponding numbers in men were in $17.5 \%(N=48)$ without diabetes and $20.4 \%(N=39)$ with diabetes $(p=0.34)$. 


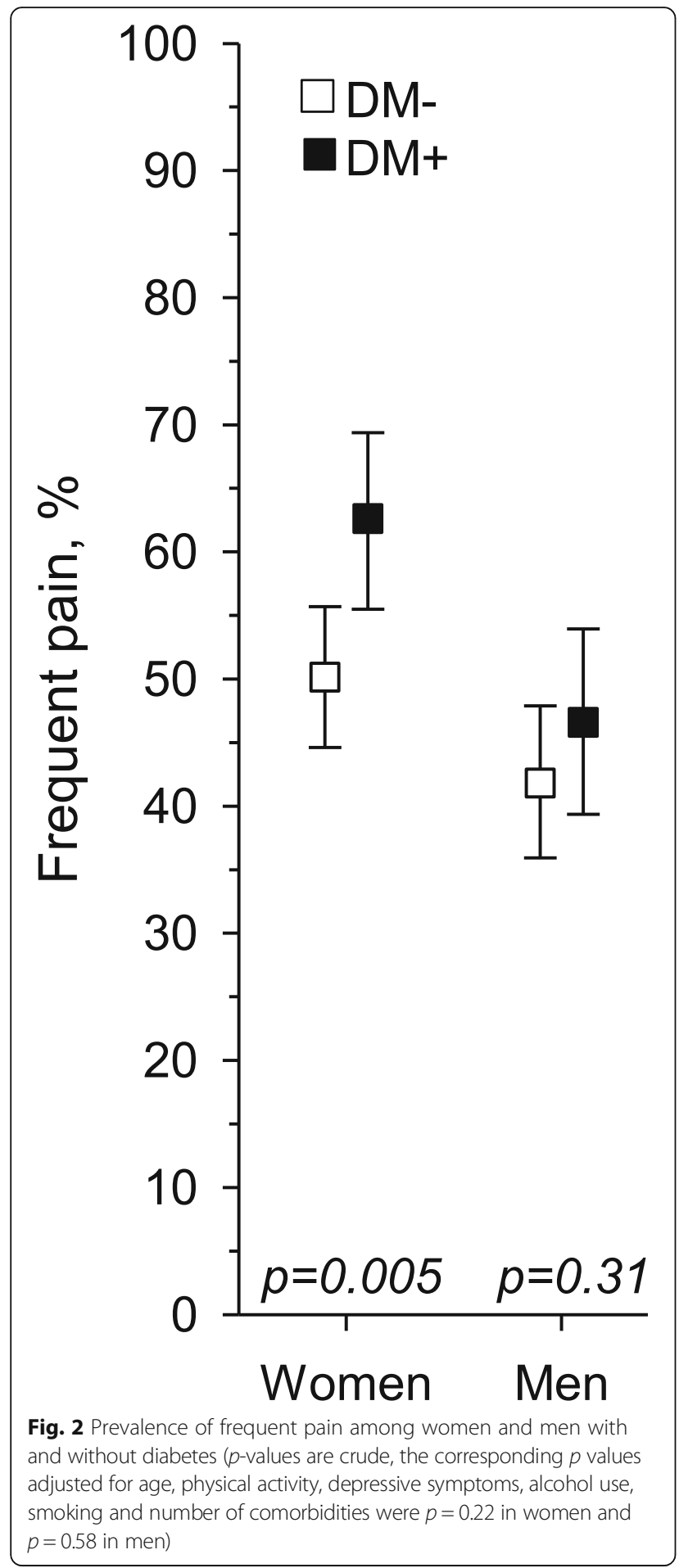

Table 2 shows the results of multinominal regression analysis conducted separately for women and men assessing the association of several variables with frequent pain. The model included diabetes (no diabetes as a reference), age (per 1-SD), depressive symptoms (GDS-15 score per 1-SD), physical activity (Kasari FIT Index per 1-SD), alcohol use (AUDIT-C per 1-SD), smoking (no

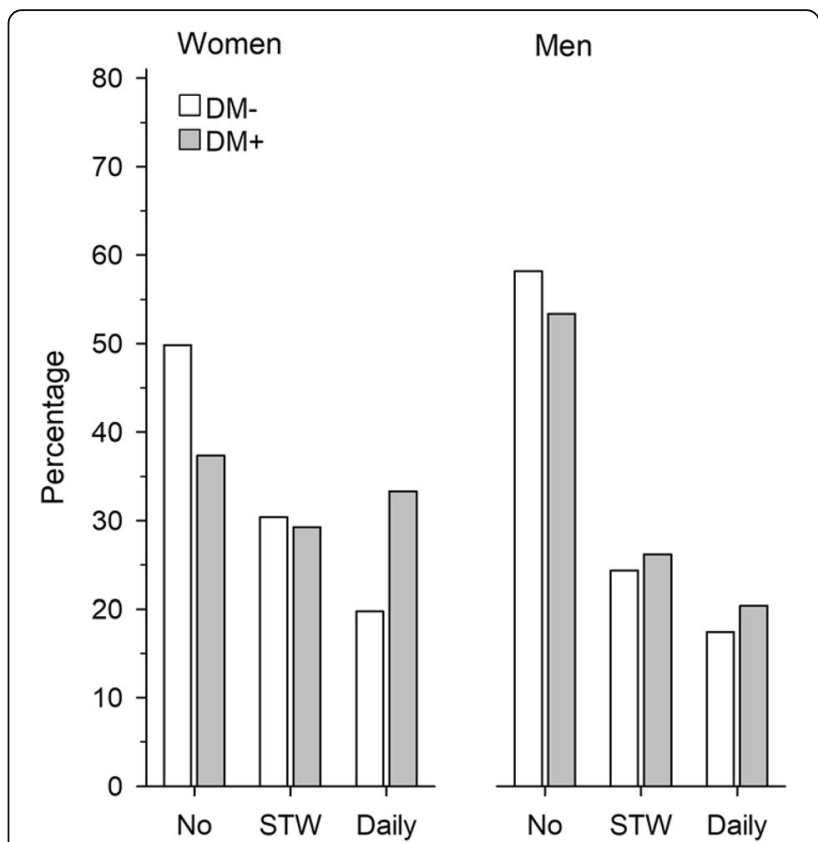

Fig. 3 Proportions of subjects without frequent pain, with pain several times a week (STW), and with daily pain among women and men with and without diabetes

smoking as reference) and number of comorbidities. In both women and men, depressive symptoms and the number of comorbidities were associated with pain experienced several times a day and daily pain. Diabetes was not associated with pain in either women or men. Neither age, depressive symptoms, physical activity, alcohol use nor smoking were associated with frequent pain.

Figure 4 presents the pain intensity and interference assessed with NRS. Diabetes was not associated with pain interference or intensity in either women or men. Pain intensity and interference were experienced higher in daily pain compared with less frequent pain in women and men. There was not any interaction in intensity or interference of pain between diabetes and pain frequency in women and men. Among persons with diabetes, significant association was found between pain intensity, interference, and HbA1C (Fig. 5).

\section{Discussion}

This primary care setting study found a high prevalence of frequent pain in older people with and without diabetes. In both women and men, there were no significant differences in the adjusted prevalence of frequent pain between those with and without diabetes. Diabetes did not explain the presence of frequent pain in either women or men, but comorbidities and depressive symptoms did. Neither was diabetes associated with the intensity or interference of pain. Furthermore, in women, 
Table 2 Factors associated with frequent pain. Results of the multinomial logistic regression analysis. Reference group: no frequent pain

\begin{tabular}{|c|c|c|c|c|}
\hline & $\begin{array}{l}\text { Pain more often } \\
\text { than once a week } \\
\text { RRR }^{\mathrm{a}} \text { (95\% Cl:) }\end{array}$ & $P$-value & $\begin{array}{l}\text { Pain daily or } \\
\text { continuously } \\
\text { RRR }^{\text {( }} 95 \% \text { Cl:) }\end{array}$ & $P$-value \\
\hline \multicolumn{5}{|l|}{ Women } \\
\hline Diabetes & $\begin{array}{l}1.09 \\
(0.67 \text { to } 1.75)\end{array}$ & 0.73 & $\begin{array}{l}1.44 \\
\text { (0.84 to } 2.47)\end{array}$ & 0.18 \\
\hline Age / 1-SD & $\begin{array}{l}0.90 \\
(0.70 \text { to } 1.15)\end{array}$ & 0.39 & $\begin{array}{l}0.98 \\
\text { (0.74 to } 1.30)\end{array}$ & 0.89 \\
\hline GDS-15 / 1-SD & $\begin{array}{l}1.49 \\
\text { (1.11 to } 1.98)\end{array}$ & 0.007 & $\begin{array}{l}1.96 \\
\text { (1.44 to } 2.65)\end{array}$ & $<0.001$ \\
\hline $\begin{array}{l}\text { Kasari-FIT } \\
\text { Index / 1-SD }\end{array}$ & $\begin{array}{l}0.98 \\
(0.76 \text { to } 1.26)\end{array}$ & 0.85 & $\begin{array}{l}0.84 \\
\text { (0.61 to } 1.14)\end{array}$ & 0.26 \\
\hline AUDIT-C / 1-SD & $\begin{array}{l}1.18 \\
(0.94 \text { to } 1.48)\end{array}$ & 0.16 & $\begin{array}{l}1.24 \\
(0.95 \text { to } 1.63)\end{array}$ & 0.12 \\
\hline Smoking & $\begin{array}{l}1.04 \\
(0.35 \text { to } 3.04)\end{array}$ & 0.95 & $\begin{array}{l}0.94 \\
(0.26 \text { to } 3.41)\end{array}$ & 0.93 \\
\hline $\begin{array}{l}\text { Number of } \\
\text { comorbidities }\end{array}$ & $\begin{array}{l}1.52 \\
\text { (1.28 to } 1.82)\end{array}$ & $<0.001$ & $\begin{array}{l}1.93 \\
(1.59 \text { to } 2.35)\end{array}$ & $<0.001$ \\
\hline \multicolumn{5}{|l|}{ Men } \\
\hline Diabetes & $\begin{array}{l}0.92 \\
(0.56 \text { to } 1.52)\end{array}$ & 0.74 & $\begin{array}{l}1.15 \\
\text { (0.64 to } 2.07)\end{array}$ & 0.64 \\
\hline Age / 1-SD & $\begin{array}{l}1.04 \\
(0.80 \text { to } 1.34)\end{array}$ & 0.78 & $\begin{array}{l}1.12 \\
(0.82 \text { to } 1.51)\end{array}$ & 0.48 \\
\hline GDS-15 / 1-SD & $\begin{array}{l}1.34 \\
(1.00 \text { to } 1.79)\end{array}$ & 0.047 & $\begin{array}{l}2.12 \\
(1.56 \text { to } 2.87)\end{array}$ & $<0.001$ \\
\hline $\begin{array}{l}\text { Kasari-FIT } \\
\text { Index / 1-SD }\end{array}$ & $\begin{array}{l}0.85 \\
(0.65 \text { to } 1.12)\end{array}$ & 0.25 & $\begin{array}{l}1.27 \\
(0.92 \text { to } 1.74)\end{array}$ & 0.14 \\
\hline AUDIT-C / 1-SD & $\begin{array}{l}1.16 \\
(0.90 \text { to } 1.48)\end{array}$ & 0.24 & $\begin{array}{l}1.04 \\
(0.77 \text { to } 1.41)\end{array}$ & 0.80 \\
\hline Smoking & $\begin{array}{l}1.19 \\
(0.60 \text { to } 2.38)\end{array}$ & 0.62 & $\begin{array}{l}0.49 \\
\text { (0.18 to } 1.37)\end{array}$ & 0.17 \\
\hline $\begin{array}{l}\text { Number of } \\
\text { comorbidities }\end{array}$ & $\begin{array}{l}1.49 \\
(1.22 \text { to } 1.82)\end{array}$ & $<0.001$ & $\begin{array}{l}1.84 \\
(1.47 \text { to } 2.30)\end{array}$ & $<0.001$ \\
\hline
\end{tabular}

SD Standard deviation, GDS-15 Geriatric Depression Scale, Kasari-FIT index person's level of physical activity (Frequency, Intensity, Time), AUDIT-C Alcohol Use Disorders Identification Test

${ }^{a}$ Relative Risk Ratio

there were differences in the reported localizations of pain between those without and with diabetes.

The prevalence of pain found in the present study is quite similar to that found in previous studies of older people $[15,19,24]$. For example, a recent populationbased study from Sweden with people aged 60 years and older reported the prevalence pain as 55\% [25]. Respectively, the prevalence of daily chronic pain was almost $30 \%$ in people aged $65-74$ years in another populationbased study [7]. In general, the prevalence of chronic pain has been found to be $50 \%$ or more among people aged 65 years or older [24]. In people with diabetes, women have more neuropathic pain than men [11]. A difference in pain occurrence and characteristics between subjects with and without diabetes has also been

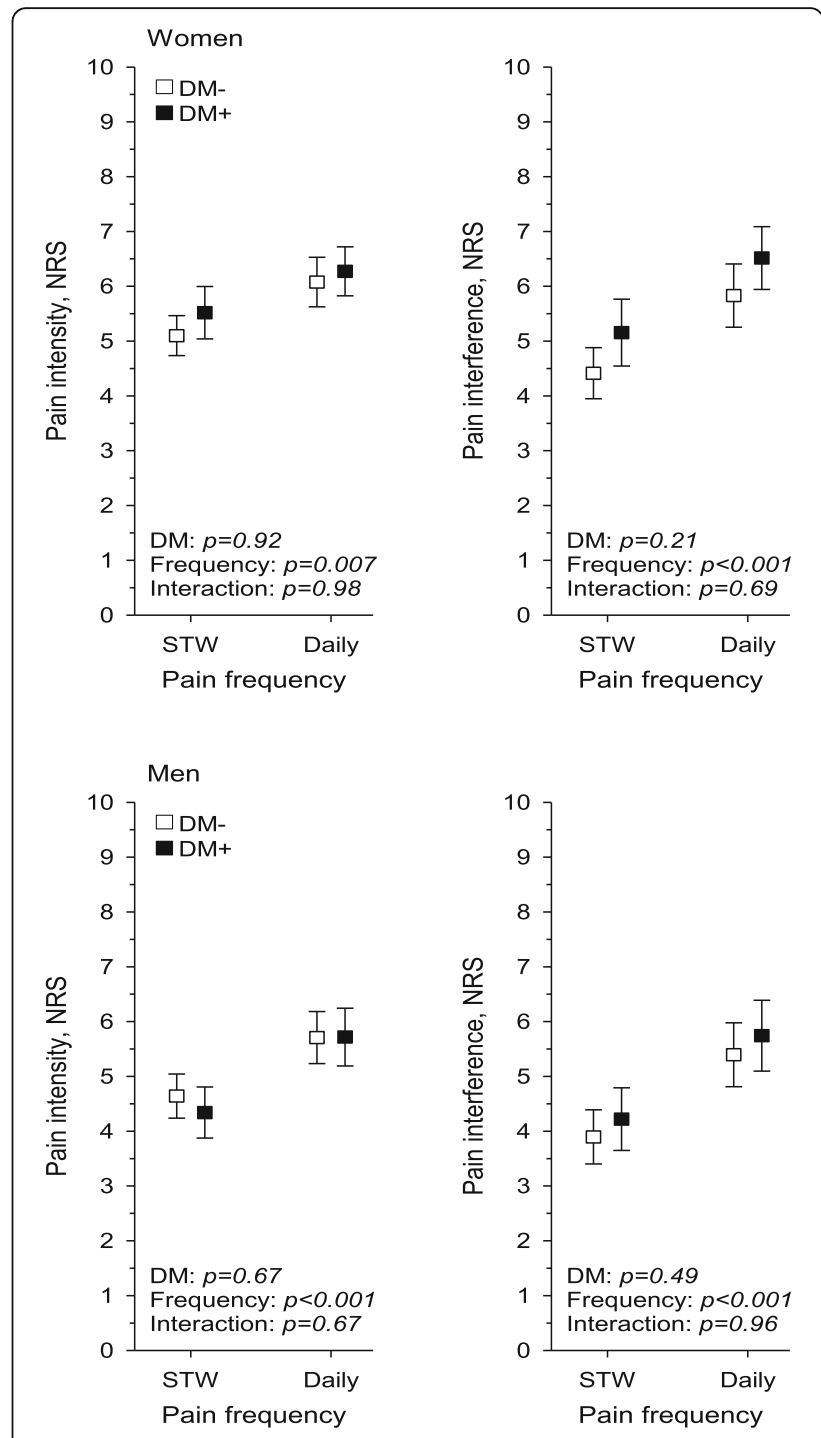

Fig. 4 Intensity and interference of pain experienced several times a week (STW) and pain experienced daily among women and men without and with diabetes

reported $[15,24]$. In the present study, osteoarthritis was more common in women with diabetes, although there was no statistical difference. Knee osteoarthritis [26] and upper extremity pain [27] are more common in people with diabetes. In a meta-analysis of 18 selected articles, it was found that people with diabetes were five times more likely to have adhesive capsulitis in their shoulders than controls [28]. Therefore, the higher prevalence of knee and shoulder pain and the higher crude prevalence of daily pain in women with diabetes compared with women without diabetes could be partly explained by the higher rate of knee osteoarthritis and chronic shoulder disorders associated with diabetes.

In the present study we were not able to detect or diagnose neuropathic pain. Based on previous studies 

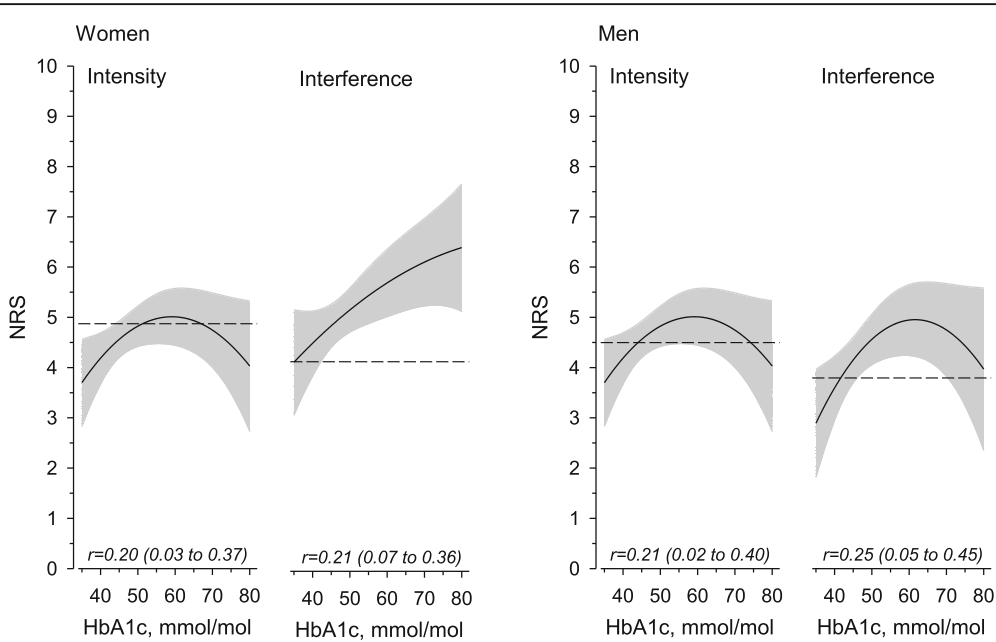

Fig. 5 Relationships between $\mathrm{HbA1c}$ and intensity and interference of pain among women and men with diabetes. The curves were derived from regression models including quadratic term of HbA1c. The curves were adjusted for age, physical activity, depressive symptoms, alcohol use, smoking and number of comorbidities. The grey area represents $95 \%$ confidence intervals. Dotted lines show means of subjects without diabetes. Adjusted curvilinear correlation was used. All curvilinear correlations were significant

exploring the occurrence of neuropathic pain in diabetic people, it could have been assumed that frequent pain would have been clearly more prevalent among diabetic people also in the present study. However, we could not detect any significant difference between the subjects without or with diabetes. Contrary to previous assumptions, this makes one hypothesize that neuropathic pain in older people is not associated with diabetes. As previously stated, we were not able to analyze neuropathic pain in the present study. Therefore, we are not able to exclude the possibility that, compared with women without diabetes, the more prevalent daily pain in those with diabetes may be due to neuropathy. However, we can conclude that, in general, frequent pain is not associated with diabetes in older homedwelling people. The HbA1c level was associated with the intensity and interference of pain. The subjects in the present study represent home-dwelling people with probably at least moderately controlled disease. Therefore, it is possible that among patients with a worse treatment situation the prevalence of pain could be higher.

The present study indicates that comorbid diseases and depressive symptoms are more significant than diabetes in pain. People with diabetes more often have depressive symptoms and depression [13, 29]. On the other hand, depression and chronic pain often co-occur [13]. Furthermore, the burden of diseases among people with diabetes is heavier $[4,30,31]$.

The strength of our study is the population-based study sample that comprehensively represents older people in a primary care setting with diabetes based on a recorded diagnosis. The response rate was high.
Our study can be considered epidemiological rather than clinical and it has also limitations. The study population was from one primary care district and therefore the generalization of these results is only possible in older Finnish semi-rural population. Our study had a cross-sectional design, therefore a cause-effect relationship cannot be presumed. Pain and other characteristics were based on self-reported data, which may be prone to inaccuracy. Although, our sample was based on the confirmed diagnosis of diabetes, the presence of other chronic diagnoses was based on questionnaire data. We were not able to define the onset or the progression of diabetes precisely although we were able to obtain the mean $\mathrm{HbAlc}$ values from the patient record. The subjects were collected according to the established diagnosis of diabetes 3 months before the questionnaire was sent. Therefore, the study sample did not include any recently diagnosed patients and we can assume that these subjects represent home-dwelling primary care patients with a substantially long history of diabetes. On the other hand, the participants of the present study do not represent frailer older people or persons with further progressed diabetes who do not live at home.

\section{Conclusions}

The findings of the present study showed that more than with diabetes itself, pain in older adults is associated with depressive symptoms and the burden of diseases. This implies that health care professionals have to consider throughout assessment and personal health care plans for home-dwelling older people suffering from frequent pain with and without diabetes. 


\section{Abbreviations}

AUDIT-C: Alcohol Use Disorders Identification Test; COPD: Chronic Obstructive Pulmonary Disease; GDS-15: Geriatric Depression Scale; HbA1c: Haemoglobin A1c; ICD-10: International Classification of Diseases; ISDM: Inner-Savo Diabetes Mellitus; NRS: The Numeric Rating Scale; SD: Standard deviation

\section{Acknowledgements}

Not applicable.

\section{Funding}

MK had a personal grant from the North Savo Cultural Foundation. The North Savo Cultural Foundation was not involved in the study design, data collection, analysis, interpretation and writing the manuscript.

\section{Availability of data and materials}

The dataset used and analysed during the current study are available from the corresponding author on reasonable request.

\section{Authors' contributions}

MK wrote the manuscript and researched data. MH and JS researched data, contributed to the discussion, and edited the manuscript. PM and MT researched data, wrote, and reviewed the manuscript. HK analyzed the data and edited the manuscript. All authors had full access to all the data (including statistical reports and tables) in the study and can take responsibility for the integrity of the data and the accuracy of the data analysis. All authors read and approved the final manuscript.

\section{Ethics approval and consent to participate}

The study protocol of the ISDM (Inner-Savo Diabetes Mellitus) study was approved by the Research Ethics Committee of the Northern Savo Hospital District, Kuopio, Finland (256/2015). The study was approved by the Inner Savo Health Care Federation of Municipalities (61 A/2015). The questionnaire included information letter about the use of data and returning of questionnaire was voluntary. The autonomy of research subjects was respected and only anonymous data were analyzed. No harm was possible for the subjects and confidentiality of the subjects and research data were protected.

\section{Consent for publication}

Not applicable.

\section{Competing interests}

The authors declares that they have no competing interests.

\section{Publisher's Note}

Springer Nature remains neutral with regard to jurisdictional claims in published maps and institutional affiliations.

\section{Author details \\ ${ }^{1}$ Institute of Public Health and Clinical Nutrition, General Practice, University of Eastern Finland, Kuopio, Finland. ${ }^{~}$ Inner Savo Health Center, Suonenjoki, Finland. ${ }^{3}$ Central Finland Central Hospital, Jyväskylä, Finland. ${ }^{4}$ School of Pharmacy, University of Eastern Finland, P.O. BOX 1627, Fl-70211 Kuopio, Finland. ${ }^{5}$ Etera Mutual Pension Insurance Company, Vantaa, Finland. ${ }^{6}$ Department of Neurosurgery, Helsinki University Hospital, Helsinki, Finland. ${ }^{7}$ Unit of Primary Health Care, Helsinki University Central Hospital, Helsinki, Finland. ${ }^{8}$ Primary Health Care Unit, Kuopio University Hospital, Kuopio, Finland.}

Received: 27 July 2017 Accepted: 6 March 2018

Published online: 15 March 2018

\section{References}

1. WHO. Global report on diabetes 2016, 2016. http://apps.who.int/iris/bitstream/ 10665/204874/1/WHO_NMH_NVI_16.3_eng.pdf?ua=1. Accessed 10 Apr 2017.

2. NCD Risk factor collaboration. Worldwide trends in diabetes since 1980; a pooled analysis of 751 population-based studies with 4,4million participants. Lancet. 2016;9:1513-30.

3. Laakso M, Groop L, Isomaa B, Honkasalo M, Juselius P, Lindström J, et al. Update on current care guideline diabetes. Duodecim. 2016;132:881-2.

4. Kirkman M, Briscoe V, Clark N, Florez H, Haas LB, Halter JB, et al. Diabetes in older adults. Diabetes Care. 2012;35:2650-65.
5. Mäntyselkä P, Korniloff K, Saaristo T, Koponen H, Erikson J, Puolijoki H, et al. Association of depressive symptoms with impaired glucose regulation, screen-detected and previously known type 2 diabetes: findings from the Finnish D2D survey. Diabetes Care. 2011;34:71-6.

6. Verhaak PF, Kerssens JJ, Dekker J, Sorbi MJ, Bensing JM. Prevalence of chronic benign pain disorder among adults: a review of the literature. Pain. 1998;77:231-9.

7. Mäntyselkä PT, Turunen JH, Ahonen RS, Kumpusalo EA. Chronic pain and poor self-rated health. J Am Med Assoc. 2003;290:2435-42.

8. Kadam UT, Thomas E, Croft PR. Is chronic widespread pain a predictor of allcause morbidity? A 3year prospective population based study in family practice. J Rheumatol. 2005:32:1341-8.

9. Macfarlane GJ, McBeth J, Silman AJ. Widespread body pain and mortality: prospective population based study. Br Med J. 2001;323:662-5.

10. Felson DT, Anderson JJ, Naimark A, Walker AM, Meenan RF. Obesity and knee osteoarthritis. The Framingham study. Ann Intern Med. 1988;1:18-24.

11. Abbott C, Malik R, van Ross E, Kulkarni J, Boulton A. Prevalence and characteristics of painful diabetic neuropathy in a large community-based diabetic population in the U.K. Diabetes Care. 2011;24:2220-4.

12. Davies M, Brophy S, Williams R, Taylor A. The prevalence, severity and impact of painful diabetic neuropathy in type 2 diabetes. Diabetes Care. 2006;29:1518-22.

13. Bair MJ, Brizendine EJ, Ackerman RT, Shen C, Kroenke K, Marrero DG Prevalence of pain and association with quality of life, depression and glycemic control in patients with diabetes. Diabetes Med. 2010;27:578-84.

14. Patel K, Guralnik J, Dansie E, Turk D. Prevalence and impact of pain among older adults in the United States: findings from the 2011 National Health and ageing trends study. Pain. 2013;154:2649.

15. Pai LW, Hung CT, Li SF, Chen LL, Chung Y, Liu HL. Musculoskeletal pain in people with and without type 2 diabetes in Taiwan: a population-based, retrospective cohort study. BMC Musculoskelet Disord. 2015;16:364.

16. Burner TW, Rosenthal AK. Diabetes and rheumatic diseases. Curr Opin Rheumatol. 2009;1:50-4.

17. Official Statistics of Finland (OSF). Population structure [e-publication]. ISSN= 1797-5395. Helsinki: Statistics Finland; 2017. http://www.stat.fi/til/vaerak/ index_en.html. Accessed 11 Dec 2017.

18. WHO. The international classification of diseases (ICD-10) diagnostic codes, 2017. 2017. http://www.who.int/classifications/icd/en/. Accessed 10 Apr 2017.

19. Mäntyselkä P, Miettola J, Niskanen L, Kumpusalo E. Chronic pain, impaired glucose tolerance and diabetes: a community-based study. Pain. 2008;137:34-40.

20. Cleeland CR, Ryan KM. Pain assessment: global use of the brief pain inventory. Ann Acad Med. 1994;23:130-8.

21. Hicks VL, Stolarczyk LM, Heyward VH, Baumgartner RN. Validation of nearinfrared interactance and skinfold methods for estimating body composition of American Indian women. Med Sci Sports Exerc. 2000;32:531-9.

22. Saunders JB, Aasland OG, Babor TF, De la Fuente JR, Grant M. Alcohol use disorders identification test (AUDIT): WHO collaborative project on early detection of persons with harmful alcohol consumption. Addiction. 1993;88:791-804.

23. Sheik JYJ, Sheik J, Yesavage J. Geriatric depression scale (GDS): recent evidence and development of a shorter version. Clin Gerontol. 1986;5:165-72.

24. Fayaz A, Croft P, Langford RM, Donaldson LJ, Jones GT. Prevalence of chronic pain in the UK: a systematic review and meta-analysis of population studies. BMJ Open. 2016;20:e010364.

25. Wranker LS, Rennemark M, Berglund J. Pain among older adults from a gender perspective: findings from the Swedish National Study on aging and care (SNAC-Blekinge). Scand J Public Health. 2016:44:258-63.

26. Sowers M, Karvonen-Gutierrez C, Palmieri-Smith R, Jacobson J, Jiang Y, Ashton-Miller J. Knee osteoarthritis is greatest in obesity with cardiometabolic clustering. Arthritis Rheum. 2009;61:1328-36.

27. Cole A, Gill T, Shanahan E, Phillips P, Taylor A, Hill C. Is diabetes associated with shoulder pain or stiffness? J Rheumatol. 2009;36:371-7.

28. Zreik N, Malik R, Charalambos P. Adhesive capsulitis of the shoulder and diabetes: a meta-analysis of prevalence. Muscles, Ligaments Tendons J. 2016;6:26-34.

29. Maraldi C, Volpato S, Penninx B, Yaffe K, Simonsick E, Strotmeyer E, et al. Diabetes mellitus, glycemic control and incident depressive symptoms among 70-to 79-year-old persons: the health, aging and body composition study. Arch Intern Med. 2007;167:1137-44.

30. Sudore RL, Karter AJ, Huang ES, Moffet HH, Laiteerapong N, Schenker Y, et al. Symptom burden of adults with type 2 diabetes across the disease course: diabetes and ageing study. JGIM. 2012;27(12):1674-81.

31. Piette JD, Kerr EA. The impact of comorbid chronic conditions on diabetes care. Diabetes Care. 2006;29:725-31. 